\title{
Incidence of Neonatal Urinary Tract Infection
}

\author{
J. M. LITTLEWOOD, P. KITE, and B. A. KITE \\ From the Department of Paediatrics and Child Health, University of Leeds; \\ and Leeds Maternity Hospital
}

The clinical manifestations of urinary tract infection in the newborn infant are extremely variable, ranging from the severe illness described by earlier authors (Sauer, 1925; Craig, 1935) to mild signs limited to anorexia and failure to gain weight (James, 1959). Asymptomatic cases have been described (Lincoln and Winberg, 1964), and bacteriuria unassociated with pyuria has been observed in the absence of clinical signs (J. M. Littlewood, unpublished).

The observed incidence of the condition varies in the experience of different clinicians. Some still regard the conditions as rare in the first month of life (C. G. H. Newman, 1967 personal communication; MacGregor and Freeman, 1968; O’Brien et al., 1968), and others see cases with relative frequency (James, 1959; Lincoln and Winberg, 1964).

The variable clinical picture may explain the widely varying incidence observed, always allowing for the occasional group of cases due to specific Esch. coli infection (Kenny et al., 1962; Sweet and Wolinsky, 1964).

During the years 1965 and 1966 a significant increase in the number of cases observed in the Leeds Maternity Hospital followed an increased search for the condition (Table I); in particular, urinalysis was performed on any infant whose clinical progress deviated in any way from the normal. It was considered that the apparent increase in incidence resulted from an increase in detection rate, suggesting that infants with mild signs had previously been overlooked. It was therefore decided to undertake a consecutive study of all 'booked' infants to determine the true incidence of urinary tract infection occurring in the newborn; in particular, to establish whether mild cases could be detected by such a screening procedure and had in fact been previously overlooked because of a paucity of physical signs and minimal clinical disturbance.

Received March 12, 1969.

\section{Screening Survey}

Included in the survey were 600 newborn infants (309 boys: 291 girls) at the Leeds Maternity Hospital, who were available for study on the 6th day of life. Those receiving antibiotics for any reason were excluded.

The study was fully consecutive over a period of 125 days between April and August 1967. Examination of the earlier series of 58 cases of neonatal urinary tract infection confirmed the lack of seasonal variation in this condition, in contrast to the winter preponderance found in older children (Stansfield, 1966).

Urine specimens were collected on the morning of the 6th day either into sterile plastic bags (Portex type) attached to the external genitalia, or as 'clean catch' mid-stream specimens. The cleansing procedure was that suggested by Pryles (1965) using 'Phisohex' for 1 minute and then swabbing 6 times with benzalkonium chloride $1: 1000$, followed by thorough drying of the perineum.

Specimens were repeated from each infant until a total bacterial count of less than 10,000 colonies $/ \mathrm{ml}$. was obtained. This was achieved on the first specimen in some $45 \%$ of those infants where urine was collected into plastic bags, and in $75 \%$ when the specimens were collected by the 'clean catch' method. Details of the normal values obtained in this series will be published elsewhere.

Cell counts were performed on uncentrifuged urine, using a Fuchs-Rosenthal chamber. A variety of stains, including that of Sternheimer and Malbin and the differential leucocyte stain of Prescott and Brodie, was employed to differentiate white cells from non-squamous epithelial cells (Sternheimer and Malbin, 1949; Prescott and Brodie, 1964).

TABLE I

Incidence of Urinary Infection by Years

\begin{tabular}{c|c|c|c}
\hline Years & Cases & Live Births & Rate per 1000 \\
\hline $1950-1963$ & 20 & 27,025 & $0 \cdot 7$ \\
1964 & 4 & 2633 & $1 \cdot 5$ \\
$1965-1967$ & 41 & 8443 & $4 \cdot 9$ \\
\hline
\end{tabular}


Quantitative bacterial counts were performed on all specimens. The surface viable count from $10 \mu \mathrm{l}$. and $1 \mu$ l. quantities of well-mixed undiluted urine were delivered onto blood agar plates and spread with a glass rod, urine being measured with sterile disposable $1 \mu \mathrm{l}$. and $10 \mu \mathrm{l}$. micro-capillary pipettes ('Microcaps', Shandon Laboratories, Ltd.). This method compares favourably with the accuracy of the classical pour plate technique (P. Kite, 1968, personal observation), while reducing time and equipment considerably.

\section{Diagnosis}

Voided urine specimens growing less than 10,000 colonies $/ \mathrm{ml}$. were considered to be uninfected. Specimens which grew more than 10,000 colonies $/ \mathrm{ml}$. were repeated, and in the majority a low count was obtained at the second or third attempt. In some, the number of organisms and cells reached such levels that infection was certain (Table II). In others, if doubt still existed after repeated voided specimens, suprapubic specimens were examined. The diagnostic criteria described by Braude and his colleagues (Braude et al., 1967) were fulfilled by the cases considered to have urinary tract infection. However, it was noted that, during the course of development or of regression of a urinary infection, these criteria might not be reached.

Some infants were discharged home before a low bacterial count could be achieved. However, the absence of pyuria and the presence of different organisms in successive specimens from the same infant suggested that true bacteriuria was not present in any of these cases. The majority of those growing more than 25,000 colonies $/ \mathrm{ml}$. were subsequently followed and none was found to be infected. However, this would not rule out a transient episode of neonatal infection.

\section{Results of Survey}

Of the 600 infants examined, 8 (7 boys and 1 girl) were found to have urinary tract infection (Table II). In 6 the evidence from voided urine was such that suprapubic specimens were considered unjustifiable. In 2 the diagnosis was confirmed by examination of suprapubic urine specimens. It is felt that 7 of the 8 cases would have been overlooked had not the screening survey been in progress. All cases were treated, though it was apparent that some were recovering spontaneously before treatment was instituted. Sufficient detail is given to show that these infants truly had urinary tract infection (Tables II, III, and IV).

\section{Discussion}

The increased recognition of neonatal urinary infection observed at the Leeds Maternity Hospital during 1965-1967, and the present finding of 8 cases in the course of a consecutive screening survey of 600 infants, support the view that urinary tract infection in the newborn infant is a relatively

TABLE II

Eight Cases of Urinary Infection-Urine Findings

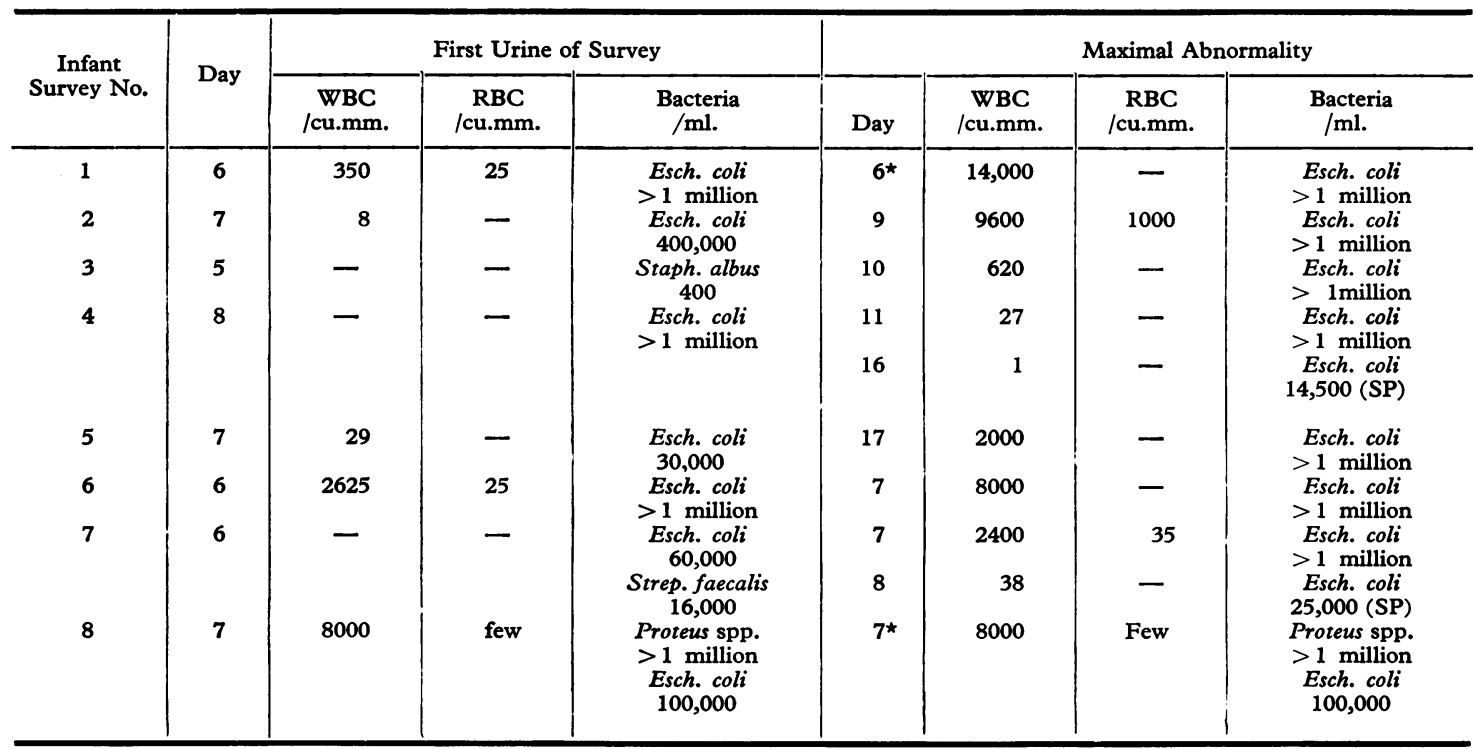

SP, suprapubic specimen. $\quad$ *Further specimen, same day. 
Incidence of Neonatal Urinary Tract Infection

TABLE III

Eight Cases of Urinary Infection-General Details

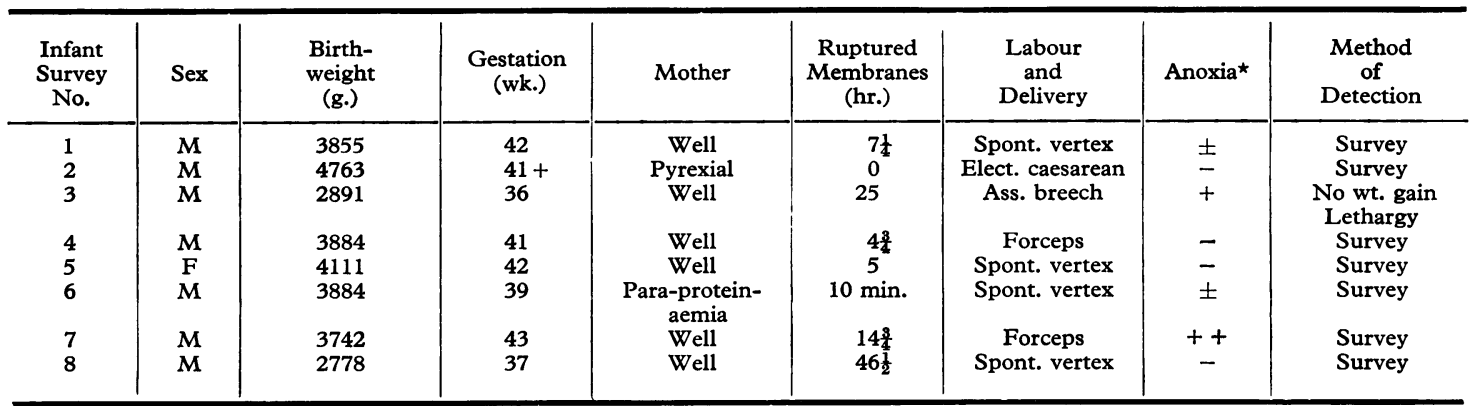

$\star_{-}$, nil; \pm , mild; + , moderate; ++ , severe.

TABLE IV

Eight Cases of Urinary Infection-Selected Investigations

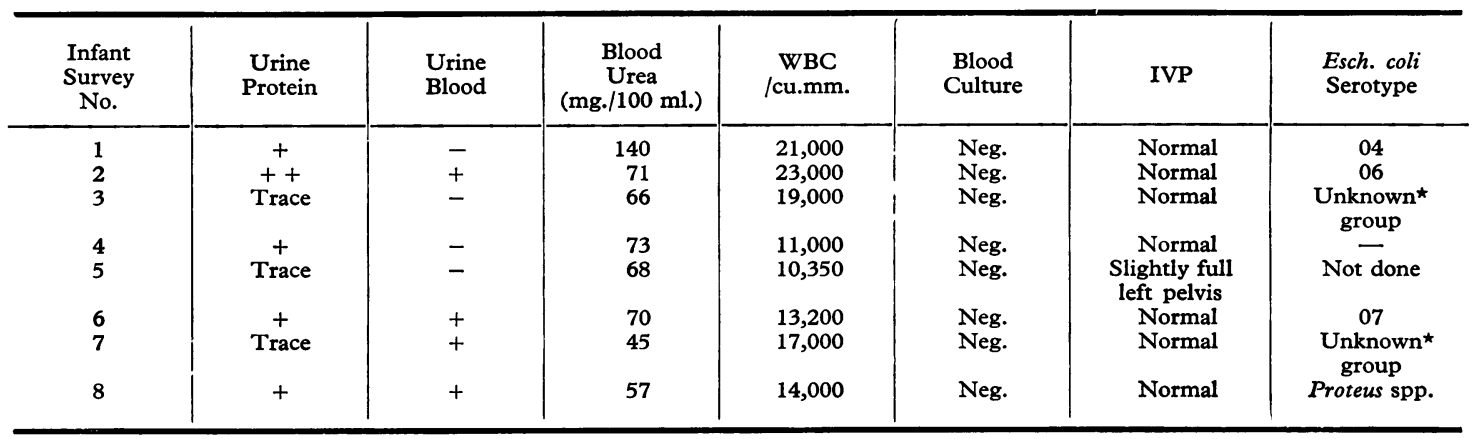

*Not one of the 20 common serotypes.

common occurrence. In the present survey, the over-all incidence was $1 \cdot 4 \%, 7$ of 309 boys $(2 \cdot 3 \%)$, and 1 of 291 girls $(0.3 \%)$.

A similar study, though not consecutive and relying for diagnosis entirely on the findings from voided urine, is that of Lincoln and Winberg (1964), who found a very similar incidence, i.e. 8 of 298 boys $(2 \cdot 7 \%)$ and 1 of 286 girls $(0 \cdot 4 \%)$.

Some indication of the previously reported incidence can be gained from a consideration of selected papers on this subject. Craig (1935) found that of his series of 61 cases, those derived from one hospital over a three-year period represented $0.9 \%$ of all live births. James (1959) found that $1.5 \%$ of infants in the London Lying-in Hospital had urinary tract infection, though a specific search was not made for the condition and the diagnosis rested upon the results of voided urine. Smellie found that the infants aged less than 1 month in her series of 200 children with urinary infection represented $0.3 \%$ of all live births occurring in University College Hospital Maternity Department during the period in question (Smellie et al., 1964). The series of both James and Smellie both showed a female preponderance and both relied on voided urine results of specimens collected into plastic bags. The diagnostic criteria adopted in these series have therefore been questioned (Braude, Forfar, and Gould, 1964).

A smaller study of 100 boys and 100 girls aged 1-4 days revealed 2 infants with urinary infection (McCarthy and Pryles, 1963).

More recently O'Doherty (1968) discovered 9 cases in 410 boys and none among 420 girls. These findings were confirmed by suprapubic bladder aspiration. In contrast, O'Brien et al. (1968) found only 1 infant with bacteriuria in 1000 newborns examined.

The findings of the present survey are considered to support the view of Lincoln and Winberg (1964) 
and O'Doherty (1968) that mildly symptomatic and asymptomatic infections are common, particularly in male infants.

It is suggested that transient, frequently selflimited, urinary tract infection is relatively common particularly in male infants, and that the majority of such infections are associated with little clinical disturbance and undergo spontaneous recovery. However, a minority progress to the severe type of infection within a period of 1 or 2 weeks, or alternatively may perhaps lead to chronic subclinical renal damage only discovered months or years later (Lincoln and Winberg, 1964).

The male preponderance, which has been noted in all series of neonatal urinary tract infection where the diagnosis is established beyond question, is an established fact.

In older children there is a marked female preponderance both in symptomatic and asymptomatic urinary tract infection. It is generally believed that this is, in part, related to the shortness of the female urethra when compared to that of the male. The male susceptibility to urinary tract infection in the newborn period may be considered as one additional manifestation of the male's wellrecognized susceptibility to infections of all types in this age-group, particularly those that are associated with bacteraemia, e.g. meningitis and sepsis of obscure origin. Asymptomatic bacteraemia may well be a common occurrence in the first days of life during initial bacterial colonization of the infant (Albers, Tyler, and Boxerbaum, 1966), and it is suggested that transient urinary tract infection may be one further manifestation of this phenomenon. Gross anatomical abnormalities of the urinary tract are uncommon in infants with this mild type of urinary tract infection.

The relation of these transient episodes of urinary tract infection to later clinical and histological renal disease is still a matter for speculation and future research.

\section{Summary}

A screening survey of 600 fully booked infants in a maternity hospital is described. 8 infants ( 7 boys and 1 girl) were found to have urinary infection, representing an over-all incidence of $1 \cdot 4 \%$ (boys $2 \cdot 3 \%$, girls $0 \cdot 3 \%$ ). 7 of these infants had signs so mild that in all probability they would have been overlooked had the survey not been in progress. The frequent occurrence of transient mild urinary tract infection, particularly in male infants, is stressed.

We would like to thank Professor R. W. Smithells for advice; Dr. W. Brumfitt for giving much helpful advice during the planning of the survey and for determining the serotypes of the organisms isolated from the infected infants; the sisters and nursing staff at the Leeds Maternity Hospital for their interest and co-operation in this study; Dr. H. G. Kohler for kindly allowing access to his laboratory; and Miss J. E. Denton for secretarial assistance.

\section{REFERENCES}

Albers, W. H., Tyler, C. W., and Boxerbaum, B. (1966). Asymptomatic bacteremia in the newborn infant. F. Pediat., 69, 193.

Braude, H., Forfar, J. O., and Gould, J. C. (1964). Urinary infection in childhood. Brit. med. F., 2, 1393.

,,--- , and McLeod, J. W. (1967). Cell and bacterial counts in the urine of normal infants and children. ibid., 4, 697.

Craig, W. S. (1935). Urinary disorders occurring in the neonatal period. Arch. Dis. Childh., 10, 337.

James, Ursula (1959). Urinary infection in the newborn. Lancet, 2, 1001.

Kenny, J. F., Medearis, D. N., Jr., Drachman, R. H., Gibson, L. E., and Klein, S. W. (1962). An outbreak of urinary tract infections and septicemia due to Escherichia coli in male infants. Amer. F. Dis. Child., 104, 461.

Lincoln, K., and Winberg, J. (1964). Studies of urinary tract infections in infancy and childhood. II. Quantitative estimation of bacteriuria in unselected neonates with special reference to the occurrence of asymptomatic infections. Acta paediat. (Uppsala), 53, 307.

McCarthy, J. M., and Pryles, C. V. (1963). Clean voided and catheter neonatal urine specimens. Amer. F. Dis. Child., 106, 473.

MacGregor, M. E., and Freeman, P. (1968). Subclassification of childhood urinary tract infections as an aid to prognosis. In Urinary Tract Infection: Proceedings of the First National Symposium. Ed. by F. W. O'Grady and W. Brumfitt. Oxford University Press, London.

O'Brien, N. G., Carroll, R., Donovan, D. E., and Dundon, S. P. (1968). Bacteriuria and leucocyte excretion in the newborn. f. Irish med. Ass., 61, 267.

O'Doherty, N. J. (1968). Urinary tract infection in the neonatal period and later infancy. In Urinary Tract Infection: Proceedings of the First National Symposium. Ed. by F. O'Grady and W. Brumfitt. Oxford University Press, London.

Prescott, L. F., and Brodie, D. E. (1964). A simple differential stain for urinary sediment. Lancet, $2,940$.

Pryles, C. V. (1965). Percutaneous bladder aspiration and other methods of urine collection for bacteriologic study. Pediatrics, 36, 128.

Sauer, L. W. (1925). Neonatal pyelitis. F. Amer. med. Ass., 85, 327.

Smellie, Jean, M., Hodson, C. J., Edwards, D., and Normand, I. C. S. (1964). Clinical and radiological features of urinary infection in childhood. Brit. med. F., 2, 1222.

Stansfield, J. M. (1966). Clinical observations relating to incidence and aetiology of urinary-tract infections in children. ibid., 1 , 631.

Sternheimer, R., and Malbin, B. I. (1949). A new stain for urinary sediments: its value in the differential diagnosis of hypertension. (Abstr.) Amer. Heart F., 37, 678.

Sweet, A. Y., and Wolinsky, E. (1964). An outbreak of urinary tract and other infections due to E. coli. Pediatrics, 33, 865 .

Correspondence to Dr. J. M. Littlewood, Department of Paediatrics and Child Health, The University of Leeds, 27 Blundell Street, Leeds 1. 